\title{
Zoonotic Pathogens in Ticks from Migratory Birds, Italy
}

\author{
Elena Battisti, Katharina Urach, Adnan Hodžić, Leonida Fusani, Peter Hufnagl, \\ Gerit Felsberger, Ezio Ferroglio, Georg Gerhard Duscher
}

Migratory birds can transport infected ticks across continents. We evaluated pathogens in ticks collected from migratory birds in Italy. We found DNA from Rickettsia aeschlimannii, $R$. africae, and $R$. raoultii bacteria, all of which can cause disease in humans. Bird migrations might facilitate the spread of these pathogens into new areas.

$\mathrm{M}$ igratory birds can be biological and mechanical carriers of viruses, bacteria, and protozoa. They also can transport infected ectoparasites, such as ticks, across continents, enabling the spread of these vectors and their pathogens into new ecologic niches. Several studies have reported the Borrelia burgdorferi sensu lato, spotted fever group (SFG) rickettsiae, and Crimean-Congo hemorrhagic fever virus (CCHFV) in Ixodes ricinus and Hyalomma marginatum ticks collected from birds that migrate annually from Africa to Europe $(1,2)$. The role of migratory birds as carriers of vectorborne pathogens in Italy is poorly understood. To assess the risk for introduction of zoonotic microbial agents in Europe by migratory birds, we investigated microorganisms in ticks collected from migratory birds in Italy.

\section{The Study}

We conducted fieldwork activities at the Ponza Ringing Station on the island of Ponza (Central Tyrrhenian Sea, Italy; $40^{\circ} 55^{\prime} \mathrm{N}, 12^{\circ} 58^{\prime} \mathrm{E}$ ) during spring (MarchMay) 2016 and 2017. We captured 744 migratory birds belonging to 20 different species (Table) during regular ringing procedures and checked them for ticks. Fourteen bird species were long-distance migrants that wintered in sub-Saharan Africa, and 6 were partial migrants, such as the blackbird (Turdus merula), the dunnock (Prunella modularis), the Eurasian blackcap

\footnotetext{
Author affiliations: Università degli Studi di Torino, Turin, Italy

(E. Battisti, E. Ferroglio); University of Veterinary Medicine Vienna, Vienna, Austria (K. Urach, A. Hodžić, L. Fusani, G.G. Duscher);

University of Vienna, Vienna (K. Urach, L. Fusani); Austrian

Agency for Health and Food Safety, Vienna (P. Hufnagl,

G. Felsberger, G.G. Duscher)
}

DOI: https://doi.org/10.3201/eid2612.181686
(Sylvia atricapilla), the European robin (Eithacus rubecula), the song thrush (Turdus philomenos), and the subalpine warbler (Sylvia cantillas).

We collected 231 engorged ticks and identified them using standard morphologic keys (3) and PCR amplification of the internal transcribed spacer (ITS) region when possible (4). We used commercial kits for RNA (High Pure Viral Nucleic Isolation Kit; Roche Diagnostics, https://diagnostics.roche.com) and DNA (High Pure PCR Template Preparation Kit; Roche Diagnostics) extraction. We used the RealStar CCHFV RT-PCR Kit 1.0 (Altona Diagnostics, https://www.altona-diagnostics.com) for CCHFV detection; we used conventional PCR with protocols described elsewhere (5) to detect DNA from Babesia spp., Anaplasma spp., Ehrlichia spp., SFG rickettsiae, and Borrelia spp. We used DNA from Babesia canis (dog 825/08, 1:10 diluted), Anaplasma phagocytophilum (cattle 2008/13, 1:10 diluted), Ehrlichia canis (clone), Rickettsia raoultii (clone) and B. burgdorferi (clone) as positive controls for each amplification.

Using PCR amplification of the ITS region, we identified 94 ticks at the species level: $H$. marginatum complex (5 larvae, 82 nymphs), I. frontalis (3 nymphs), I. ventalloi (3 nymphs), and Amblyomma marmoreum (1 nymph). Amplification of the ITS region failed in the remaining ticks, identifying only the genus; these ticks were mostly Hyalomma spp. (1 larva, 118 nymphs) or Ixodes spp. (3 larvae, 14 nymphs, and 1 adult).

Of the analyzed ticks, 50 tested positive for SFG rickettsiae DNA; the overall prevalence was $21.7 \%$ (95\% CI 16.8\%-27.4\%). To determine the species, we amplified a fragment of the ompA gene in all the SFG rickettsiae-positive ticks (5). Positive amplicons were sequenced by LGC Genomics (https://www.lgcgroup. com) and compared with sequences deposited in GenBank. Results revealed $R$. aeschlimannii DNA in 47 (94.0\% [95\% CI 83.8\%-97.9\%]) of 50 ticks (Table). We identified 46 sequences identical to an $R$. aeschlimanni strain documented from Egypt (GenBank accession no. HQ335157), Turkey (GenBank accession no. MF379299), and Italy (GenBank accession no. MH532239) and 1 sequence identical to $R$. aeschlimanni strain RH (GenBank 
Table. Sampled bird species, ticks, and Rickettsia PCR positivity, Italy, 2016-2017*

\begin{tabular}{|c|c|c|c|c|c|c|}
\hline \multirow{2}{*}{ Year, bird species } & \multirow{2}{*}{$\begin{array}{l}\text { No. } \\
\text { birds }\end{array}$} & \multirow{2}{*}{$\begin{array}{l}\text { Tick species } \\
\text { found }\end{array}$} & \multirow{2}{*}{$\begin{array}{l}\text { No. pathogen-positive } \\
\text { ticks/no. tested ticks }\end{array}$} & \multicolumn{3}{|c|}{ Rickettsia } \\
\hline & & & & R. aeschlimanni & R. africae & R. raoultii \\
\hline \multicolumn{7}{|l|}{2016} \\
\hline Barn swallow (Hirundo rustica) & 18 & NA & NA & & & \\
\hline Blackbird (Turdus merula) & 1 & Ixodes ventalloi & $0 / 1$ & & & \\
\hline \multirow[t]{2}{*}{ Black redstart (Phoenicuros ochruros) } & 29 & I. ventalloi & $0 / 2$ & & & \\
\hline & & Hyalomma sp. & $1 / 3$ & 1 & 0 & 0 \\
\hline Eurasian blackcap (Sylvia atricapilla) & 1 & NA & NA & & & \\
\hline European robin (Erithacus rubecula) & 22 & I. frontalis & $0 / 1$ & & & \\
\hline Garden warbler (Sylvia borin) & 83 & NA & NA & & & \\
\hline Icterine warbler (Hippolais icterina) & 19 & Hyalomma sp. & $1 / 2$ & 0 & 1 & 0 \\
\hline Northern weathear (Oenanthe & 1 & Hyalomma sp. & $1 / 1$ & 1 & 0 & 0 \\
\hline \multicolumn{7}{|l|}{ oenanthe) } \\
\hline Pied flycatcher (Ficedula hypoleuca) & 21 & Hyalomma sp. & $1 / 5$ & 1 & 0 & 0 \\
\hline Redstart (Phoenicuros phoenicuro) & 14 & Hyalomma sp. & $7 / 9$ & 7 & 0 & 0 \\
\hline Spotted flycatcher (Muscicapa striata) & 25 & NA & NA & & & \\
\hline Subalpine warbler (Sylvia cantillas) & 1 & I. frontalis & $0 / 1$ & & & \\
\hline Tree pipit (Anthus trivialis) & 1 & Hyalomma sp. & $1 / 2$ & 1 & 0 & 0 \\
\hline \multirow[t]{2}{*}{ Whinchat (Saxicola rubetra) } & 38 & I. frontalis & $0 / 1$ & & & \\
\hline & & Hyalomma sp. & $4 / 13$ & 4 & 0 & 0 \\
\hline \multirow[t]{2}{*}{ Whitethroat (Sylvia communis) } & 92 & Ixodes sp. & $0 / 1$ & & & \\
\hline & & Hyalomma sp. & $10 / 24$ & 9 & 0 & 1 \\
\hline Willow warbler (Phylloscopus trochilus) & 1 & NA & NA & & & \\
\hline Wood warbler (Phylloscopus sibilatrix) & 1 & Hyalomma sp. & $0 / 3$ & & & \\
\hline \multicolumn{7}{|l|}{2017} \\
\hline Barn swallow (H. rustica) & 20 & Hyalomma sp. & $0 / 1$ & & & \\
\hline Black redstart ( $P$. ochruros) & 3 & H. rufipes & $1 / 1$ & 0 & 1 & 0 \\
\hline Collared flycatcher (Ficedula albicollis) & 1 & H. rufipes & $1 / 1$ & 1 & 0 & 0 \\
\hline Dunnock (Prunella modularis) & 1 & Hyalomma sp. & $0 / 1$ & & & \\
\hline Eurasian blackcap (S. atricapilla) & 48 & NA & NA & & & \\
\hline European robin (E. rubecula) & 39 & H.rufipes & $2 / 10$ & 2 & 0 & 0 \\
\hline Garden warbler (S. borin) & 30 & NA & NA & & & \\
\hline Icterine warbler $(H$. icterina $)$ & 41 & NA & NA & & & \\
\hline Northern weathear $(O$. oenanthe) & 1 & H. rufipes & $1 / 1$ & 1 & & \\
\hline Pied flycatcher (F. hypoleuca) & 30 & Hyalomma sp. & $0 / 1$ & & & \\
\hline Redstart ( $P$. phoenicuros) & 25 & H. rufipes & $8 / 12$ & 8 & 0 & 0 \\
\hline Song thrush & 4 & $H$. rufipes & $1 / 1$ & 1 & 0 & 0 \\
\hline (Turdus philomenos) & & Hyalomma sp. & $0 / 3$ & & & \\
\hline Spotted flycatcher (M. striata) & 24 & H. rufipes & $1 / 2$ & 1 & 0 & 0 \\
\hline Subalpine warbler (S. cantillas) & 1 & Hyalomma sp. & $0 / 1$ & & & \\
\hline \multirow[t]{2}{*}{ Tree pipit (A. trivialis) } & 2 & Amblyomma & $1 / 1$ & 1 & 0 & 0 \\
\hline & & $\begin{array}{l}\text { marmoreum } \\
\text { Hyalomma sp. }\end{array}$ & $0 / 1$ & & & \\
\hline Whinchat (S. rubetra) & 43 & H. rufipes & $5 / 7$ & 5 & 0 & 0 \\
\hline Whitethroat (S. communis) & 57 & H. rufipes & $2 / 5$ & 2 & 0 & 0 \\
\hline Willow warbler ( $P$. trochilus) & 1 & Hyalomma sp. & $0 / 1$ & & & \\
\hline \multirow[t]{2}{*}{ Wood warbler ( $P$. sibilatrix) } & 5 & H. rufipes & $1 / 1$ & 1 & 0 & 0 \\
\hline & & Hyalomma sp. & $0 / 4$ & & & \\
\hline
\end{tabular}

accession no. HM050286) from Senegal; the latter strain differed from the others by $1 \mathrm{nt}$ (T instead of $\mathrm{C}$ at nt 425 ). Two (4.0\% [95\% CI 1.1\%-13.5\%]) sequences were identical to R. africae (GenBank accession no. HQ335132), and 1 (2.0\% [95\% CI 0.4\%-10.5\%]) sequence was identical to R. raoultii (GenBank accession no. MF166732). We also screened a subset of positive ticks using primers targeting a fragment of the gltA gene (5), confirming the results obtained with the ompA gene. No ticks tested positive for other microorganisms.

\section{Conclusions}

Although ticks of the $H$. marginatum species complex (i.e., H. marginatum, H. rufipes, H. turanicum, and
H. isaaci) are the most widespread ticks in Africa, they also have been found in some countries in Europe, such as the United Kingdom (6). These tick species are also vectors for $\mathrm{CCHFV}$, which occurs mainly in Africa and southeastern Europe and can cause life-threatening disease in humans. Hyalomma ticks are vectors and reservoirs of this virus; birds, which are the primary hosts for the immature stages of these ticks, can maintain and spread the virus into new areas through migration (7).

$R$. aeschlimannii and $R$. africae, which are zoonotic bacterial species endemic to Africa, are transmitted by ticks belonging to the genera Hyalomma and Amblyomma. However, these bacteria have also been detected in ticks from other regions, such as Oceania, the 
Caribbean islands, and Europe (7-9). Autochthonous cases of human rickettsiosis caused by $R$. aeschlimannii have been recently described in Greece (10) and Italy (11). We detected $R$. africae in $H$. rufipes and $R$. raoultii in Hyalomma sp., which are not known vectors for these pathogens. Because we did not test the birds for Rickettsia spp. and the ticks were engorged, we cannot exclude the possibility that the ticks acquired these microorganisms by feeding on positive birds. Nevertheless, our results agree with those observed in a study in Italy (12) and confirm the circulation of these Rickettsia species into areas to which they are not endemic. They also highlight the role of migratory birds in the passive transportation of infected ticks.

Although no ticks tested positive for CCHFV in our study, some studies report this virus in H. marginatum complex ticks attached to birds migrating from Africa to Europe (13). Migratory birds might have contributed to the establishment of the CCHFV in Spain (14). Moreover, climate change could cause prolonged, warmer, and drier summers and autumns. These seasonal changes might lead to the establishment of autochthonous populations of Hyalomma ticks in areas previously free of these vectors. Finally, RNA of another relevant human pathogen, the recently discovered Alkhurma hemorrhagic virus (15), has been detected in ticks of the H. marginatum complex.

In summary, we found zoonotic bacteria in ticks carried by birds across their migratory routes and assessed the risk for pathogen introduction in Italy. However, further studies are needed to clarify the role of these ticks in the epidemiology of zoonotic pathogens.

\section{Acknowledgments}

We thank Marco Pombi and 2 anonymous reviewers who provided helpful comments and suggestions to improve this manuscript.

\section{About the Author}

Dr. Battisti is a postdoctoral researcher at the Department of Veterinary Science, University of Turin. Her main research focuses on zoonotic s transmitted by vectors.

\section{References}

1. Comstedt P, Bergström S, Olsen B, Garpmo U, Marjavaara L, Mejlon H, et al. Migratory passerine birds as reservoirs of Lyme borreliosis in Europe. Emerg Infect Dis. 2006;12:108795. https://doi.org/10.3201/eid1207.060127

2. Palomar AM, Portillo A, Mazuelas D, Roncero L, Arizaga J, Crespo A, et al. Molecular analysis of Crimean-Congo hemorrhagic fever virus and Rickettsia in Hyalomma marginatum ticks removed from patients (Spain) and birds (Spain and Morocco), 2009-2015. Ticks Tick Borne Dis. 2016;7:983-7. https://doi.org/10.1016/j.ttbdis.2016.05.004
3. Palomar AM, Portillo A, Santibáñez P, Mazuelas D, Arizaga J, Crespo A, et al. Crimean-Congo hemorrhagic fever virus in ticks from migratory birds, Morocco. Emerg Infect Dis. 2013;19:260-3. https://doi.org/10.3201/ eid1902.121193</jrn>

4. Lv J, Wu S, Zhang Y, Chen Y, Feng C, Yuan X, et al. Assessment of four DNA fragments (COI, 16S rDNA, ITS2, $12 \mathrm{~S}$ rDNA) for species identification of the Ixodida (Acari: Ixodida). Parasit Vectors. 2014;7:93. https://doi.org/10.1186/1756-3305-7-93

5. Hodžić A, Fuehrer HP, Duscher GG. First molecular evidence of zoonotic bacteria in ticks in Bosnia and Herzegovina. Transbound Emerg Dis. 2017;64:1313-6. https:/ / doi.org/10.1111/tbed.12473

6. Jameson LJ, Morgan PJ, Medlock JM, Watola G, Vaux AGC. Importation of Hyalomma marginatum, vector of Crimean-Congo haemorrhagic fever virus, into the United Kingdom by migratory birds. Ticks Tick Borne Dis. 2012;3:95-9. https://doi.org/10.1016/ j.ttbdis.2011.12.002

7. Palomar AM, Portillo A, Mazuelas D, Roncero L, Arizaga J, Crespo A, et al. Molecular analysis of Crimean-Congo hemorrhagic fever virus and Rickettsia in Hyalomma marginatum ticks removed from patients (Spain) and birds (Spain and Morocco), 2009-2015. Ticks Tick Borne Dis. 2016;7:983-7. https:// doi.org/10.1016/j.ttbdis.2016.05.004

8. Kelly PJ. Rickettsia africae in the West Indies. Emerg Infect Dis. 2006;12:224-6. https:/ / doi.org/10.3201/eid1202.050903

9. Eldin C, Mediannikov O, Davoust B, Cabre O, Barré N, Raoult D, et al. Emergence of Rickettsia africae, Oceania. Emerg Infect Dis. 2011;17:100-2. https:/ / doi.org/10.3201/ eid1701.101081

10. Germanakis A, Chochlakis D, Angelakis E, Tselentis Y, Psaroulaki A. Rickettsia aeschlimannii infection in a man, Greece. Emerg Infect Dis. 2013;19:1176-7. https:// doi.org/10.3201/eid1907.130232

11. Tosoni A, Mirijello A, Ciervo A, Mancini F, Rezza G, Damiano F, et al.; Internal Medicine Sepsis Study Group. Human Rickettsia aeschlimannii infection: first case with acute hepatitis and review of the literature. Eur Rev Med Pharmacol Sci. 2016;20:2630-3.

12. Toma L, Mancini F, Di Luca M, Cecere JG, Bianchi R, Khoury C, et al. Detection of microbial agents in ticks collected from migratory birds in central Italy. Vector Borne Zoonotic Dis. 2014;14:199-205. https://doi.org/10.1089/vbz.2013.1458

13. Mancuso E, Toma L, Polci A, d'Alessio SG, Di Luca M, Orsini M, et al. Crimean-Congo hemorrhagic fever virus genome in tick from migratory bird, Italy. Emerg Infect Dis. 2019;25:1418-20. https:// doi.org/10.3201/eid2507.181345

14. Negredo A, de la Calle-Prieto F, Palencia-Herrejón E, Mora-Rillo M, Astray-Mochales J, Sánchez-Seco MP, et al.; Crimean Congo Hemorrhagic Fever Madrid Working Group. Autochthonous Crimean-Congo hemorrhagic fever in Spain. N Engl J Med. 2017;377:154-61. https:/ / doi.org/10.1056/ NEJMoa1615162

15. Hoffman T, Lindeborg M, Barboutis C, Erciyas-Yavuz K, Evander M, Fransson T, et al. Alkhurma hemorrhagic fever virus RNA in Hyalomma rufipes ticks infesting migratory birds, Europe and Asia Minor. Emerg Infect Dis. 2018;24:87982. https:/ / doi.org/10.3201/eid2405.171369>

Address for correspondence: Georg Gerhard Duscher, Institute of Parasitology, Department of Pathobiology, University of Veterinary Medicine, Veterinaerplatz 1, 1210 Vienna, Austria; email: georg.duscher@vetmeduni.ac.at 